\title{
A Mobile Terminal-based Nomogram for Early Predicting Severity of Acute Pancreatitis
}

\author{
Na Shi \\ Sichuan University West China Hospital \\ Xiaoxin Zhang \\ Sichuan University West China Hospital \\ Wenhua He \\ First Affiliated Hospital of Nanchang University \\ Lihui Deng \\ Sichuan University West China Hospital \\ Lan Li \\ Sichuan University West China Hospital \\ Ping Zhu \\ Sichuan University West China Hospital \\ Liang Xia \\ First Affiliated Hospital of Nanchang University \\ Tao Jin \\ Sichuan University West China Hospital \\ Thomas Ward \\ University of Liverpool \\ Peter Sztamary \\ University of Liverpool \\ Wenhao Cai \\ Sichuan University West China Hospital

\section{Linbo Yao} \\ Sichuan University West China Hospital \\ Xinmin Yang \\ Sichuan University West China Hospital \\ Ziqi Lin \\ Sichuan University West China Hospital \\ Kun Jiang \\ Sichuan University West China Hospital \\ Jia Guo
}

Sichuan University West China Hospital

Xiaonan Yang

Sichuan University West China Hospital

Vikesh K. Singh

Johns Hopkins Medical Institutions: Johns Hopkins Medicine

Robert Sutton

University of Liverpool

John A. Windsor

University of Auckland

Nonghua Lu

First Affiliated Hospital of Nanchang University

Yin Zhu

First Affiliated Hospital of Nanchang University

Wei Huang ( $\nabla$ wei.huang.scu@vip.163.com )

Sichuan University West China Hospital https://orcid.org/0000-0001-8659-322X

Qing Xia

Sichuan University West China Hospital 


\section{Research Article}

Keywords: Acute pancreatitis, Persistent organ failure, Nomogram, Receiver-operating characteristic curve, C-index, Clinical utility

Posted Date: August 3rd, 2021

DOI: https://doi.org/10.21203/rs.3.rs-764041/v1

License: (c) (i) This work is licensed under a Creative Commons Attribution 4.0 International License. Read Full License 


\section{Abstract}

Background: Early prediction of the severity of acute pancreatitis (AP) is important but there is no preferred method in China. We aimed to develop and validate a simple-to-use predictive nomogram for persistent organ failure (POF) on admission in patients with AP.

Methods: Data from 816 consecutive patients was obtained from internal (Chengdu) retrospective datasets and formed the training cohort for nomogram development. Data from 398 and 880 consecutive patients from internal (Chengdu) and external (Nanchang) prospective datasets formed the validation cohorts (all admitted $<48$ hours of symptom onset). Univariate and multivariate logistic regressions were used to identify independent prognostic factors to establish the nomogram for POF. The calibration curves, concordance index (C-index), decision curve analysis (DCA), and clinical impact curve (CIC) were used to evaluate the performance of the nomogram and its clinical utility. The area under the receiver-operating characteristic curve (AUC) with $95 \% \mathrm{Cl}$ and likelihood ratio as well as post-test probability were applied.

Measurements and main results: Age, respiratory rate, albumin, lactate dehydrogenase, oxygen support, and pleural effusion were identified as independent prognostic factors for POF and were included in the nomogram model (web-based calculator: https://shina.shinyapps.io/DynNomapp/). This predictive nomogram had good predictive ability for POF (C-indexes of $0.88,0.91$ and 0.81 for the training and two validation cohorts) and promising clinical utility (DCA: better or equivalent than prognostic scores; CIC: high clinical net benefit). The AUC of (0.91 [0.88-0.94] and 0.81 [0.79$0.84]$ ), negative likelihood ratio (NLR 0.11 and 0.29 ), post-test probability of negative $(0.9 \%$ and $6.7 \%$ ) of the nomogram were superior in predicting POF than all other routinely used clinical prognostic scoring systems in both validation cohorts. Similar findings were observed for predicting major infection (superior to other prognostic scores) and mortality (superior or equally to others).

Conclusions: The validated nomogram comprises 6 independent prognostic factors to predict major clinical outcomes of patients with AP in two distinct Chinese centers. This mobile terminal-based nomogram should be validated in other settings and considered for clinical practice and trial allocation, until more accurate biomarkers are discovered.

\section{Introduction}

Acute pancreatitis (AP) is a protean and heterogenous disease with a spectrum of severity ranging from mild to critical [1]. The early prediction of the severity of AP is a cornerstone of management because it informs clinical decisions about triage, transfer and intervention [2]. Early prediction is also important in the research setting, where the accurate allocation of patients into trial arms based on predicted severity is critical for the testing of treatments for AP. The key determinants of AP severity are organ failure and infected pancreatic necrosis [3, 4]. With the recent improvements in treating infected pancreatic necrosis, persistent organ failure (POF) has become the most important determinant for mortality [5-9], and is the basis for the grade of severe AP (SAP) in the revised Atlanta classification (RAC) [10]).

Since the Ranson score was introduced in 1974 [11], more than 20 prognostic scores have been studied for AP severity prediction [12]. However, their clinical utility is limited by an accuracy of predicting POF at circa 75\% and many of them are cumbersome to use [13]. Recent systematic reviews and meta-analyses conclude that current early predictors of POF [14], infected pancreatic necrosis [14], and mortality [12] do not have sufficient accuracy for the decision making in individual patients. The ideal predictor of POF would be applied on patient admission and within 24 hours of the onset of symptoms. It would be cost-effective, easy to use and have an accuracy between $95-100 \%$. Considerable progress has been made in identifying serum biomarkers to stratify early risk and severity in patients with AP [15]. However, due to their rapid time-course changes in serum concentration, nonspecificity, cost, complexity, and suboptimal accuracy, none of the biochemical biomarkers have been adopted into routine clinical practice. In recent years, different nomograms have been applied for predicting severity (mortality) [16-19], splanchnic vein thrombosis [20], abdominal infection [21], computed tomography index for assessing AP outcomes [22] and catheter drainage in necrotizing AP [23, 24] as well as for oral refeeding intolerance during hospital stay [25] and new-onset diabetes after AP [26] (Table 1). However, of the 4 studies investigated the predictive value of nomograms for severity or mortality, 3 used online Critical Care Database (Medical Information Mart for Intensive Care III database [MIMIC-III] [16, 18], elCU Collaborative Research Database [eICU-CRD] [17]) and 1 was retrospective [19] in nature. Besides, none of these studies reported the time of symptom onset to hospital admission. Therefore, the early prediction of AP severity at primary admission or early transfer remains to a challenge. 
Table 1

Summarize of the present developed nomograms in AP

Nomograms for predicting SAP or mortality

\begin{tabular}{|c|c|c|c|c|c|c|c|c|c|c|c|}
\hline & \multirow[t]{2}{*}{$\begin{array}{l}\text { Predicted } \\
\text { outcome }\end{array}$} & & \multirow[t]{2}{*}{ Study design } & \multirow{2}{*}{$\begin{array}{l}\text { Symptom } \\
\text { onset } \\
\text { time }\end{array}$} & \multirow{2}{*}{$\begin{array}{l}\text { Data } \\
\text { collection } \\
\text { time }\end{array}$} & \multirow{2}{*}{$\begin{array}{l}\text { Indicators } \\
\text { of the } \\
\text { Nomogram }\end{array}$} & \multicolumn{2}{|c|}{$\begin{array}{l}\text { Training } \\
\text { cohort }\end{array}$} & \multicolumn{2}{|c|}{$\begin{array}{l}\text { Validation } \\
\text { cohort }\end{array}$} & \multirow[t]{2}{*}{ Main findings } \\
\hline & & & & & & & $\mathrm{N}$ & $\begin{array}{l}\text { C- } \\
\text { index }\end{array}$ & $\mathrm{N}$ & C-index & \\
\hline \multirow[t]{3}{*}{ Jiang et al } & Mortality & $\begin{array}{l}\text { 30- } \\
\text { day }\end{array}$ & MIMIC-III & NA & $\begin{array}{l}\text { Within } 24 \\
\mathrm{~h}\end{array}$ & $\begin{array}{l}\text { age, ALT, } \\
\text { RDW, BUNN }\end{array}$ & 228 & 0.751 & 114 & 0.875 & \multirow{3}{*}{$\begin{array}{l}\text { Nomogram > } \\
\text { BISAP > SOFA > } \\
\text { SIRS for long- } \\
\text { term mortality } \\
\text { both in cohorts }\end{array}$} \\
\hline & & $\begin{array}{l}180- \\
\text { day/ }\end{array}$ & & & $\begin{array}{l}\text { Within } 24 \\
\mathrm{~h}\end{array}$ & $\begin{array}{l}\text { age, WBC, } \\
\text { RDW, SCR }\end{array}$ & & 0.758 & & 0.856 & \\
\hline & & $\begin{array}{l}1- \\
\text { year }\end{array}$ & & & & & & & & & \\
\hline
\end{tabular}

$2019[16]$

\begin{tabular}{|c|c|c|c|c|c|c|c|c|c|c|}
\hline $\begin{array}{l}\text { Li et al } \\
2020 \text { [17] }\end{array}$ & $\begin{array}{l}\text { In-hospital } \\
\text { mortality }\end{array}$ & elCU-CRD & NA & $\begin{array}{l}\text { Within } 24 \\
\text { h }\end{array}$ & $\begin{array}{l}\text { age, BUN } \\
\text { and lactate }\end{array}$ & 378 & 0.896 & 123 & 0.892 & $\begin{array}{l}\text { The nomogram } \\
\text { and APACHE IV } \\
\text { demonstrated } \\
\text { comparable } \\
\text { power in } \\
\text { predicting in- } \\
\text { hospital } \\
\text { mortality. }\end{array}$ \\
\hline \multirow[t]{2}{*}{$\begin{array}{l}\text { Xu et al } \\
2020 \text { [18] }\end{array}$} & SAP & MIMIC-III & NA & $\begin{array}{l}\text { On } \\
\text { admission }\end{array}$ & $\begin{array}{l}\text { SOFA, } \\
\text { hemoglobin, } \\
\text { albumin, } \\
\text { TBIL, BÚN }\end{array}$ & 708 & 0.855 & 477 & 0.879 & \multirow[t]{2}{*}{$\begin{array}{l}\text { Nomogram > } \\
\text { SOFA / OASIS } \\
\text { for SAP and } \\
\text { mortality in both } \\
\text { cohorts. }\end{array}$} \\
\hline & $\begin{array}{l}\text { In-hospital } \\
\text { mortality }\end{array}$ & & & $\begin{array}{l}\text { On } \\
\text { admission }\end{array}$ & $\begin{array}{l}\text { Age, SOFA, } \\
\text { WBC, TBIL, } \\
\text { albumin }\end{array}$ & & 0.821 & & 0.822 & \\
\hline $\begin{array}{l}\text { Cao et al } \\
2021 \text { [19] }\end{array}$ & SAP & Retrospective & NA & $\begin{array}{l}\text { Within } 24 \\
\mathrm{~h}\end{array}$ & $\begin{array}{l}\text { Sex, } \mathrm{Ca}^{2+} \\
\text { SCR, NE\%, } \\
\text { LYMPH\%, } \\
\text { EO\% }\end{array}$ & 571 & 0.69 & 150 & 0.71 & $\begin{array}{l}\text { No comparison } \\
\text { with others. }\end{array}$ \\
\hline
\end{tabular}

\section{Other nomograms in AP}

\begin{tabular}{|c|c|c|c|c|c|c|c|}
\hline & \multirow[t]{2}{*}{ Predicted outcome } & \multirow[t]{2}{*}{ Statistical methods } & \multirow[t]{2}{*}{ Indicators of the Nomogram } & \multicolumn{2}{|c|}{$\begin{array}{l}\text { Training } \\
\text { cohort }\end{array}$} & \multicolumn{2}{|c|}{$\begin{array}{l}\text { Validation } \\
\text { cohort }\end{array}$} \\
\hline & & & & $\mathrm{N}$ & $\begin{array}{l}\text { C- } \\
\text { index }\end{array}$ & $\mathrm{N}$ & $\begin{array}{l}\text { C- } \\
\text { index }\end{array}$ \\
\hline $\begin{array}{l}\text { Hollemans } \\
\text { et al } \\
2016[23]\end{array}$ & $\begin{array}{l}\text { Success of catheter } \\
\text { drainage in infected } \\
\text { necrotizing pancreatitis }\end{array}$ & $\begin{array}{l}\text { Univariate and multivariate logistic } \\
\text { regression }\end{array}$ & $\begin{array}{l}\text { Sex, percentage of } \\
\text { pancreatic necrosis, density } \\
\text { collection, multiple organ } \\
\text { failure }\end{array}$ & 130 & 0.76 & NA & NA \\
\hline $\begin{array}{l}\text { Zhou et al } \\
2016 \text { [20] }\end{array}$ & $\begin{array}{l}\text { Symptomatic splanchnic } \\
\text { vein thrombosis in } \\
\text { necrotizing acute } \\
\text { pancreatitis }\end{array}$ & $\begin{array}{l}\text { Univariate and multivariate logistic } \\
\text { regression }\end{array}$ & $\begin{array}{l}\text { Balthazar's CT score, intra- } \\
\text { abdominal pressure and } \\
\text { superior mesenteric vein } \\
\text { thrombosis }\end{array}$ & 104 & 0.842 & NA & NA \\
\hline $\begin{array}{l}\text { Bevan et } \\
\text { al } \\
2017 \text { [25] }\end{array}$ & Oral feeding intolerance & $\begin{array}{l}\text { Univariate and multivariate logistic } \\
\text { regression }\end{array}$ & $\begin{array}{l}\text { Day } 2 \text { GCSI } \\
\text { nausea/vomiting subs-core, } \\
\text { etiology }\end{array}$ & 217 & NA & NA & NA \\
\hline $\begin{array}{l}\text { Ma et al } \\
2019 \text { [26] }\end{array}$ & $\begin{array}{l}\text { New-onset diabetes } \\
\text { mellitus after the first } \\
\text { attack of acute } \\
\text { pancreatitis }\end{array}$ & $\begin{array}{l}\text { Univariate and multivariate logistic } \\
\text { regression }\end{array}$ & $\begin{array}{l}\text { Age, BMI, glucose, } \\
\text { triglyceride, and LDL-C }\end{array}$ & 616 & 0.686 & NA & NA \\
\hline
\end{tabular}

SAP, severe acute pancreatitis; MIMIC-III, Medical Information Mart for Intensive Care III; NA, not available; ALT, alanine aminotransferase; RDW, red cell distribution width; BUN, blood urea nitrogen; WBC, white blood cell count; SCR, serum creatinine; BISAP, Bedside Index of Severity in Acute Pancreatitis; SOFA, Sequential Organ Failure Assessment; SIRS, Systemic Inflammatory Response Syndrome; ICU, intensive care unit; elCU-CRD, elCU Collaborative Research Database; APACHE, Acute Physiology, Age, and Chronic Health Evaluation; TBIL, total bilirubin; OASIS, Outcome and Assessment Information Set; NE\%, neutrophil ratio; LYMPH\%, lymphocyte Ratio; eosinophil ratio, EO\%; GCSI, Gastroparesis Cardinal Symptom Index; LDL-C, low density lipoprotein-cholesterol; PCD, percutaneous catheter drainage; CTSI, computed tomography severity index. 


\begin{tabular}{|c|c|c|c|c|c|c|c|}
\hline \multicolumn{8}{|c|}{ Nomograms for predicting SAP or mortality } \\
\hline $\begin{array}{l}\text { Bellam et } \\
\text { al } \\
2019 \text { [24] }\end{array}$ & $\begin{array}{l}\text { Success of percutaneous } \\
\text { catheter drainage in } \\
\text { patients with acute } \\
\text { pancreatitis having acute } \\
\text { fluid collection }\end{array}$ & $\begin{array}{l}\text { Univariate and multivariate logistic } \\
\text { regression }\end{array}$ & $\begin{array}{l}\text { volume of collection after } \\
\text { PCD and organ failure } \\
\text { resolution after PCD }\end{array}$ & 51 & 0.915 & NA & NA \\
\hline \multirow{6}{*}{$\begin{array}{l}\text { Gupta et } \\
\text { al } \\
2021[22]\end{array}$} & Mortality & \multirow[t]{6}{*}{ Binomial logistic regression } & $\begin{array}{l}\text { Pancreatic necrosis, ascites, } \\
\text { pleural effusion }\end{array}$ & \multirow[t]{6}{*}{103} & 0.79 & \multirow[t]{6}{*}{20} & 0.74 \\
\hline & ICU stay & & $\begin{array}{l}\text { Number of collection, } \\
\text { pleural effusion }\end{array}$ & & 0.66 & & 0.70 \\
\hline & hospital stay $\geq 4$ weeks & & $\begin{array}{l}\text { Pancreatic necrosis, number } \\
\text { of collection, amount PE }\end{array}$ & & 0.75 & & 0.77 \\
\hline & Readmission & & $\begin{array}{l}\text { Number of collection, } \\
\text { coeliac artery }\end{array}$ & & 0.70 & & 0.52 \\
\hline & ICU stay $\geq 2$ weeks & & $\begin{array}{l}\text { Pancreatic necrosis, largest } \\
\text { dimension of collection, } \\
\text { pleural effusion }\end{array}$ & & 0.83 & & 0.45 \\
\hline & SAP & & $\begin{array}{l}\text { Number of collection, liver } \\
\text { steatosis }\end{array}$ & & 0.64 & & 0.69 \\
\hline $\begin{array}{l}\text { Zhu et al } \\
2021 \text { [21] }\end{array}$ & Intra-abdominal infection & LASSO regression & $\begin{array}{l}\text { Intra-abdominal pressure, } \\
\text { APACHE II score, CTSI, ICU } \\
\text { admission, and severity } \\
\text { grade }\end{array}$ & 417 & 0.99 & 294 & 0.98 \\
\hline \multicolumn{8}{|c|}{$\begin{array}{l}\text { SAP, severe acute pancreatitis; MIMIC-III, Medical Information Mart for Intensive Care III; NA, not available; ALT, alanine aminotransferase; RDW, red } \\
\text { cell distribution width; BUN, blood urea nitrogen; WBC, white blood cell count; SCR, serum creatinine; BISAP, Bedside Index of Severity in Acute } \\
\text { Pancreatitis; SOFA, Sequential Organ Failure Assessment; SIRS, Systemic Inflammatory Response Syndrome; ICU, intensive care unit; elCU-CRD, } \\
\text { elCU Collaborative Research Database; APACHE, Acute Physiology, Age, and Chronic Health Evaluation; TBIL, total bilirubin; OASIS, Outcome and } \\
\text { Assessment Information Set; NE\%, neutrophil ratio; LYMPH\%, lymphocyte Ratio; eosinophil ratio, EO\%; GCSI, Gastroparesis Cardinal Symptom } \\
\text { Index; LDL-C, low density lipoprotein-cholesterol; PCD, percutaneous catheter drainage; CTSI, computed tomography severity index. }\end{array}$} \\
\hline
\end{tabular}

The aim of this study was to (1) develop and validate a nomogram for early predicting POF in patients with AP and (2) compare the performance of the nomogram with conventional prognostic scores in two distinct large tertiary hospitals in China.

\section{Methods}

\section{Study design and ethics}

This study followed the STROBE guidelines [27] for observational studies. The study protocol was approved by respective Institutional Review Board in these two hospitals. Data were obtained from two AP cohorts in West China Hospital of Sichuan University (WCH/SCU): retrospective datasets between 1st July 2009 and 30th June 2013 as the training cohort [9]; prospective datasets between 1st January 2016 and 31 th August 2017 as the internal validation cohort [28]. For the purpose of external validation, we obtained the datasets from AP database of The First Affiliated Hospital of Nanchang University from January 2005 to December 2012 [29].

\section{Inclusion and exclusion criteria}

Inclusion criteria: (1) AP diagnosed by the RAC [10], (2) age > 18 or $\leq 80$ years old, (3) time from abdominal pain onset to admission $\leq 48$ hours, and (3) primary admission directly to $\mathrm{WCH} / \mathrm{SCU}[9,28]$.

Exclusion criteria included patients admitted to another hospital prior to WCU/SCU, re-admitted during the same episode of AP, chronic pancreatitis, pancreatic neoplasia, trauma, or pregnancy as AP etiologies, and advanced pre-existing comorbidities consistent with previous studies [6, 9, 28, 30]. The external validation cohort also contained transferred patients and the cases with the final formulized nomogram factors missing were excluded.

\section{Definitions, variables, and outcome measures}

Demographic features collected on admission, such as age, gender, underlying disease to score Charlson co-morbidity index and abdominal pain onset time to admission. Vital signs, laboratory parameters (routine blood and biochemical indices), details of oxygen treatment and presence of pleural effusion that were mostly obtained from nonenhanced computed tomography scan on admission. Experienced PhD students and resident doctors specializing in management of AP were stringently trained for data collection according to pre-defined proforma and standard operating procedures in both centers. Each proforma was checked and signed off by attending or more senior doctors.

\section{Etiologies}


Hypertriglyceridemia as the etiology was defined as admission serum triglyceride (TG) level > $1000 \mathrm{mg} / \mathrm{dl}(11.3 \mathrm{mmol} / \mathrm{l})$ or TG > $500 \mathrm{mg} / \mathrm{dl}$ (5.65 $\mathrm{mmol} / \mathrm{l}$ ) with lipemic serum or a previous history of hypertriglyceridemia [31,32]. Biliary etiology was considered if gallstones or biliary sludge was present on radiological imaging or had alanine aminotransferase over three times the upper limit of normal [33, 34]. Alcohol excess was referred if with drinking history $>35$ standard drinks per week for $>5$ years [35] or was deduced according to our center's own practice according to the drinking history after ruling out other etiologies.

\section{Organ failure, local complication, and major infection}

POF was defined as at least one of the systems (respiratory, circulatory, and renal) having a SOFA score $\geq 2$ and lasting $\geq 48$ hours [36]. Acute necrotic collection and acute peripancreatic fluid collection were defined as per RAC criteria [10]. Major infection included infected pancreatic necrosis, bacteremia, or pneumonia alone or in combination [37]. Mortality (including those who were automatically discharged with persistent multiple organ failure and had high possibility of death) and length of hospital stay were recorded for the index hospitalization.

The prognostic scores evaluated in this study were National Early Warning Score (NEWS) [38], Systemic Inflammatory Response Syndrome (SIRS) [39], Bedside Index for Severity in Acute Pancreatitis (BISAP) [40], modified Glasgow criteria [41], Acute Physiology and Chronic Health Examination (APACHE) II [42], and Sequential Organ Failure Assessment (SOFA) [43]. These were all calculated on admission (or within 6 hours of admission if absent earlier in minority of cases).

\section{Statistical analysis}

Continuous variables were expressed as median with 25th -75th percentile and were compared by Mann-Whitney $U$ test (2 groups) or Kruskal-Wallis $H$ test (3 groups). Categorical data were reported as number with percentage and were compared by means of $\chi^{2}$ or Fisher's exact test.

The significance of each variable in the training cohort was assessed by univariate logistic regression analysis for investigating the independent risk factors of POF. All variables significantly associated with POF were candidates for stepwise multivariate analysis and the results were used to formulate a nomogram. The predictive performance of the nomogram was measured by concordance index (C-index) and calibration with 1000 bootstrap samples to decrease the overfit bias [44]. Decision curve analysis (DCA) and clinical impact curve (CIC) were used to evaluate the clinical utility of the novel model [45]. DCA is a simple, novel method of evaluating predictive models with decision analyses of diagnostic and prognostic tests by using a risk-benefit ratio [46]. CIC is another type of plot produced by Decision Curve that shows the estimated number who would be declared to having high risk for each risk threshold and visually shows the proportion of those who are cases (true positives) [45].

The area under curve (AUC) of the receiver operating characteristic (ROC) curves with $95 \%$ confidence intervals (CI) of all potential predictors were calculated. An AUC of $0.5,0.7$ to $0.8,0.8$ to 0.9 , and $>0.9$ was suggestive of no discrimination, acceptable, excellent and outstanding, respectively [47]. Statistical significance of the AUCs between any two predictors was compared by method of DeLong et al [48]. The optimum cut-offs for sensitivity, specificity, positive likelihood ratio (PLR), negative likelihood ratio (NLR) and post-test probabilities of the top predictors were derived from the ROC curves. The interpretation of the likelihood ratio was as follows: > 10, 5-10, 2-5, 1-2, and 1 representing large with often conclusive, moderate, small, minimal, and no change, respectively, for increase in the likelihood of disease (positive test), while $0.5-1.0,0.2-0.5,0.1-0.2$, and $<0.1$ representing minimal, small, moderate, and large with often conclusive, respectively for decrease in the likelihood of disease (negative test).

The analyses were performed using IBM SPSS Statistics V26.0 software (SPSS, IBM Corp; Armonk, New York, USA) and R software version 4.0.4 (http://www.Rproject.org). Two-tailed $P$ value with statistical significance set at $<0.05$ was used for all tests.

\section{Results}

\section{Patient characteristics}

There were 816 and 398 patients in the training and internal validation cohorts, respectively, that met the eligibility criteria (Additional file 1: Figure S1A, B). After removing missing values, the external validation cohort contained 880 records. The demographic profiles of the three cohorts are outlined in Table 2. The median age was 45 years old and about $70 \%$ patients were male in both training and internal validation cohorts, while median age of the external cohort was 50 years old and $60.6 \%$ were male. Hypertriglyceridemia ( $32.7 \%$ and $42 \%)$ was the most common etiology in our internal two cohorts when biliary (57.5\%) was the main etiology in the external cohort. The baseline characteristics of patients as per RAC of the training and validation cohorts are displayed in Additional file 2: Table S1a-c, respectively. These results are similar to previous published studies [9, 28, 29]. 
Table 2

Baseline characteristics and clinical outcomes in training and validation cohorts

\begin{tabular}{|c|c|c|c|}
\hline \multirow[t]{3}{*}{ Variables } & \multirow{2}{*}{$\begin{array}{l}\text { Training cohort } \\
\mathbf{n = 8 1 6}\end{array}$} & \multicolumn{2}{|c|}{ Validation cohorts } \\
\hline & & & (External) \\
\hline & & $n=398$ & $n=880$ \\
\hline \multicolumn{4}{|l|}{ Demographics } \\
\hline Age, years* & $45(37-55)$ & $45(38-51)$ & $50(41-62)$ \\
\hline Male & $568(69.6)$ & $273(68.6)$ & $533(60.6)$ \\
\hline Charlson comorbidity index* & $1(0-1)$ & $1(0-2)$ & $0(0-0)$ \\
\hline \multicolumn{4}{|l|}{ Etiology } \\
\hline Biliary & $230(28.2)$ & 78 (19.6) & $506(57.5)$ \\
\hline Hypertriglyceridemia & 267 (32.7) & $167(42.0)$ & $184(20.9)$ \\
\hline Alcohol & $30(3.7)$ & $31(7.8)$ & $61(6.9)$ \\
\hline Unknown or others & $291(35.6)$ & $122(30.7)$ & $129(14.7)$ \\
\hline Time to admission, hours* & $12(7-24)$ & $15(9-24)$ & NA \\
\hline \multicolumn{4}{|l|}{ Clinical outcomes } \\
\hline Persistent organ failure & $80(9.8)$ & $30(7.5)$ & $178(20.2)$ \\
\hline Respiratory & $77(9.4)$ & $30(7.5)$ & 169 (19.2) \\
\hline Circulatory & $14(1.7)$ & $2(0.5)$ & $12(1.4)$ \\
\hline Renal & $10(1.2)$ & $3(0.8)$ & $28(3.2)$ \\
\hline Need for HDU/ICU & $59(7.2)$ & $29(7.3)$ & $168(19.1)$ \\
\hline \multicolumn{4}{|l|}{ Local complication } \\
\hline Acute peripancreatic fluid collection & $163(20.0)$ & 119 (29.9) & $332(37.7)$ \\
\hline Acute necrotic collection & $59(7.2)$ & $55(13.8)$ & $204(23.2)$ \\
\hline Major infection & $45(5.5)$ & $20(5.0)$ & $53(6.0)$ \\
\hline Infected pancreatic necrosis & $12(1.5)$ & $9(2.3)$ & $36(4.1)$ \\
\hline Bacteremia & $15(1.8)$ & $6(1.5)$ & $13(1.5)$ \\
\hline Lung & $35(4.3)$ & $9(2.3)$ & $18(2.0)$ \\
\hline Necrosectomy & $14(1.7)$ & $13(3.3)$ & $17(1.9)$ \\
\hline Mortality & $10(1.2)$ & $4(1.0)$ & $20(2.3)$ \\
\hline \multicolumn{4}{|l|}{ RAC } \\
\hline Mild & $508(62.3)$ & $190(47.7)$ & $328(37.3)$ \\
\hline Moderately severe & $228(27.9)$ & 178 (44.7) & $374(42.5)$ \\
\hline Severe & $80(9.8)$ & $30(7.5)$ & $178(20.2)$ \\
\hline Length of hospital stay (days)* & $9(6-13)$ & $8(6-11)$ & $8(6-13)$ \\
\hline
\end{tabular}

\section{Developing and validating a nomogram for predicting POF}

Demographic characteristics of clinical importance, vital signs, routine blood tests, biochemical indices, and other established risk factors on admission, but not existing prognostic scores were considered as candidate variables for developing the predictive nomogram. The independent prognostic factors for POF after univariate and multivariate logistic regression analysis were age (OR 1.03 [95\% $\mathrm{Cl} 1.01-0.05]$; $P=0.01)$, respiratory rate (1.25 [1.10-1.42]; $P=0.001)$, albumin (0.92 [0.87-0.98]; $P=0.013)$, lactate dehydrogenase (LDH; 1.002 [1.000-1.003]; $P=0.036)$, oxygenation (5.17 
[2.91-9.20]; $P<0.001$ ), and pleural effusion (3.61 [1.97-6.61]; $P<0.001$ ) (Table 3). These variables were finally used to construct our predictive nomogram (Fig. 1A). To facilitate the clinical application of our findings, we developed a mobile terminal-based calculator

(https://shina.shinyapps.io/DynNomapp/) of the predictive nomogram (Fig. 1B, C). In the training cohort, the C-index of the nomogram was 0.88 (Fig. 2A) with good consistency between the predicted SAP and the actual POF observed shown by the calibration curve (Fig. 2B). In the internal validation cohort, the C-index of the nomogram for predicting SAP reached 0.91 (Fig. 2C) and with a better consistency (Fig. 2D) compared to the training cohort. The C-index was 0.81 (Fig. 2E) in the external validation cohort and the calibration curve also showed satisfactory consistency (Fig. 2F). 
Table 3

Univariate and multivariate logistic regression analysis with stepwise variable selection

\begin{tabular}{|c|c|c|c|c|}
\hline \multirow[t]{2}{*}{ Variables } & \multicolumn{2}{|l|}{ Univariate analysis } & \multicolumn{2}{|l|}{ Multivariate analysis } \\
\hline & OR $(95 \% \mathrm{Cl})$ & $P$ value & OR $(95 \% \mathrm{Cl})$ & $P$ value \\
\hline \multicolumn{5}{|l|}{ Demographics } \\
\hline Age, years & $1.036(1.019-1.053)$ & $<0.001$ & 1.030 (1.007-1.053) & 0.01 \\
\hline Gender & $1.263(0.777-2.053)$ & 0.346 & & \\
\hline Charlson comorbidity index & $0.96(0.684-1.346)$ & 0.811 & & \\
\hline Etiology & $0.861(0.711-1.043)$ & 0.127 & & \\
\hline Time to admission, hours & $1.005(0.984-1.026)$ & 0.658 & & \\
\hline \multicolumn{5}{|l|}{ Admission vital signs } \\
\hline Body temperature & $1.377(0.902-2.102)$ & 0.138 & & \\
\hline Respiratory rate & $1.352(1.207-1.514)$ & $<0.001$ & $1.249(1.099-1.420)$ & 0.001 \\
\hline Heart rate & $1.029(1.016-1.042)$ & $<0.001$ & $1.006(0.989-1.023)$ & 0.499 \\
\hline \multicolumn{5}{|c|}{ Admission laboratory parameters } \\
\hline Amylase, IU/I & $1.000(1.000-1.001)$ & 0.001 & $1.000(1.000-1.000)$ & 0.448 \\
\hline Lipase, IU/I & $1.000(1.000-1.000)$ & 0.096 & & \\
\hline White blood cell, $10^{9} / \mathrm{l}$ & $1.112(1.062-1.165)$ & $<0.001$ & $1.085(0.854-1.379)$ & 0.505 \\
\hline Neutrophils, $10^{9} / \mathrm{I}$ & $1.115(1.063-1.169)$ & $<0.001$ & $0.974(0.755-1.257)$ & 0.839 \\
\hline Lymphocytes, $10^{9} / \mathrm{I}$ & $0.958(0.709-1.293)$ & 0.777 & & \\
\hline NLR & $1.007(0.996-1.018)$ & 0.186 & & \\
\hline Platelet, $10^{9} / /$ & $1.000(0.997-1.003)$ & 0.868 & & \\
\hline Hematocrits, I/I & $2.973(0.023-377.4)$ & 0.659 & & \\
\hline Hemoglobin, g/l & $1.011(1.000-1.022)$ & 0.057 & & \\
\hline ALT, IU/I & $1.001(0.999-1.002)$ & 0.247 & & \\
\hline AST, IU/I & $1.001(1.000-1.002)$ & 0.125 & & \\
\hline Albumin, g/l & $0.884(0.844-0.925)$ & $<0.001$ & $0.924(0.868-0.984)$ & 0.013 \\
\hline Glucose, mmol/l & $1.063(1.021-1.106)$ & 0.003 & $1.003(0.945-1.066)$ & 0.915 \\
\hline Urea, mmol/l & $1.219(1.124-1.321)$ & $<0.001$ & $1.105(0.973-1.256)$ & 0.123 \\
\hline Creatinine, $\mu \mathrm{mol} / \mathrm{l}$ & $1.012(1.005-1.018)$ & $<0.001$ & $1.001(0.992-1.009)$ & 0.904 \\
\hline Triglycerides, mmol/l & $1.017(0.993-1.041)$ & 0.162 & & \\
\hline Cholesterol, mmol/l & 1.041 (0.977-1.109) & 0.211 & & \\
\hline Lactate dehydrogenase, IU/I & $1.003(1.002-1.004)$ & $<0.001$ & $1.002(1.000-1.003)$ & 0.036 \\
\hline Calcium, mmol/l & $0.093(0.033-0.263)$ & $<0.001$ & $0.719(0.174-2.970)$ & 0.648 \\
\hline Oxygen supporting & $5.722(3.486-9.393)$ & $<0.001$ & $5.170(2.905-9.202)$ & $<0.001$ \\
\hline Pleural effusion & $3.802(2.318-6.237)$ & $<0.001$ & $3.611(1.973-6.610)$ & $<0.001$ \\
\hline
\end{tabular}

\section{Clinical utility of the nomogram}

The nomogram of training cohort (Fig. 3A, B), internal validation cohort (Fig. 3C, D), and external validation cohort (Fig. 3E, F) exhibited better or equal clinical utility (DCA) with the other prognostic scores and had good clinical net benefits (CIC) for the identification of SAP patients. Of particular note, the nomogram outperformed all other indices in the internal validation cohort suggesting that it could help clinicians to obtain maximum benefit when making clinical decisions as it showed more benefit than the extreme situation of diagnosing POF in all patients or none.

Page 9/19 


\section{Comparison the nomogram with prognostic scores}

Prediction of POF

There were $9.8 \%(80 / 816), 7.5 \%$ (30/398) and 20.2\% (178/880) patients that developed POF in the training, internal validation and external validation cohorts, respectively (Table 2). BISAP had the highest predictive value (AUC 0.89 [0.87-0.91], PLR 7.24) for POF compared with the other indices (Table 4; upper pane/) and followed by the nomogram (AUC 0.88 [0.86-0.91], PLR 4.26), both higher than APACHE II (0.79 [0.76-0.82], PLR 3.61) and Glasgow (0.75 [0.72-0.78], PLR 2.89) ( $P<0.05$, Table S2) in training cohort. The nomogram showed the best predictive value (0.91 [0.88-0.94], PLR 7.89, Table 4; middle panel) in internal validation cohort and higher than all other clinical scoring systems ( $P<0.05$; Additional file 2: Table S2), followed by NEWS (0.79 [0.75-0.83], PLR 2.80) and BISAP (0.75 [0.71-0.79], PLR 5.72). In addition, the NLR (0.11) of the nomogram ranked the best among all the comparative indices, with the lowest post-test probability of not being POF $(0.9 \%)$ indicating a high negative prediction value. The nomogram also ranked the top AUC (0.81 [0.79-0.84]), lowest NLR (0.29) and post-test probability of not being POF (6.7\%) among all the indices in the external validation cohort (Table 4; lower panel), with the AUC higher than NEWS, BISAP, APACHE II and SIRS ( $P<0.05$; Additional file 2: Table S2). 
Table 4

Predictive value of the nomogram and clinical prognostic scores for persistent organ failure

\begin{tabular}{|c|c|c|c|c|c|c|c|c|c|}
\hline & AUC & $\begin{array}{l}P \\
\text { value }\end{array}$ & $\begin{array}{l}\text { Cut- } \\
\text { off }\end{array}$ & $\begin{array}{l}\text { Sensitivity } \\
\text { (\%) }\end{array}$ & $\begin{array}{l}\text { Specificity } \\
(\%)\end{array}$ & PLR & NLR & $\begin{array}{l}\text { Post_Prob_Pos } \\
(\%)\end{array}$ & $\begin{array}{l}\text { Post_Prob_Neg } \\
\text { (\%) }\end{array}$ \\
\hline \multicolumn{10}{|c|}{ Training cohort ( $9.8 \%$ pre-test probability) } \\
\hline Nomogram & $\begin{array}{l}0.88(0.86- \\
0.91)\end{array}$ & $<0.001$ & 91.2 & 78.8 & 81.5 & 4.26 & 0.26 & 31.7 & 2.8 \\
\hline NEWS & $\begin{array}{l}0.85(0.82- \\
0.87)\end{array}$ & $<.001$ & 4 & 66.3 & 88 & 5.54 & 0.38 & 37.6 & 4 \\
\hline BISAP & $\begin{array}{l}0.89 \text { (0.87- } \\
0.91)\end{array}$ & $<.001$ & 2 & 78.8 & 89.1 & 7.24 & 0.24 & 44.0 & 2.5 \\
\hline APACHE II & $\begin{array}{l}0.79(0.76- \\
0.82)\end{array}$ & $<.001$ & 6 & 61.3 & 83 & 3.61 & 0.47 & 28.2 & 4.9 \\
\hline SIRS & $\begin{array}{l}0.84(0.81- \\
0.86)\end{array}$ & $<.001$ & 2 & 91.3 & 74.6 & 3.59 & 0.12 & 28.1 & 1.3 \\
\hline Glasgow & $\begin{array}{l}0.75(0.72- \\
0.78)\end{array}$ & $\begin{array}{l}<.001 \\
0.0\end{array}$ & 2 & 61.3 & 78.8 & 2.89 & 0.49 & 23.9 & 5.1 \\
\hline SOFA & $\begin{array}{l}0.87(0.84- \\
0.89)\end{array}$ & $<.001$ & 1 & 85 & 81.2 & 4.53 & 0.18 & 33.0 & 1.9 \\
\hline \multicolumn{10}{|l|}{$\begin{array}{l}\text { Validation } \\
\text { cohort }\end{array}$} \\
\hline \multicolumn{10}{|c|}{ Internal validation (7.5\% pre-test probability) } \\
\hline Nomogram & $\begin{array}{l}0.91(0.88- \\
0.94)\end{array}$ & $<.001$ & 79.2 & 90 & 88.6 & 7.89 & 0.11 & 39.1 & 0.9 \\
\hline NEWS & $\begin{array}{l}0.79(0.75- \\
0.83)\end{array}$ & $\hat{0} .001$ & 4 & 70.0 & 75.0 & 2.80 & 0.40 & 18.5 & 3.1 \\
\hline BISAP & $\begin{array}{l}0.75(0.71- \\
0.79)\end{array}$ & $\begin{array}{l}< \\
0.001\end{array}$ & 2 & 46.7 & 91.9 & 5.72 & 0.58 & 31.7 & 4.5 \\
\hline APACHE II & $\begin{array}{l}0.66(0.61- \\
0.71)\end{array}$ & 0.005 & 6 & 36.7 & 89.4 & 3.46 & 0.71 & 21.9 & 5.4 \\
\hline SIRS & $\begin{array}{l}0.68(0.63- \\
0.72)\end{array}$ & $<0.001$ & 2 & 70.0 & 61.4 & 1.81 & 0.49 & 12.8 & 3.8 \\
\hline Glasgow & $\begin{array}{l}0.69(0.64- \\
0.73)\end{array}$ & $\begin{array}{l}<.001 \\
0.00\end{array}$ & 3 & 46.7 & 80.7 & 2.42 & 0.66 & 16.4 & 5.1 \\
\hline SOFA & $\begin{array}{l}0.73(0.68- \\
0.77)\end{array}$ & $<.001$ & 2 & 63.3 & 75.8 & 2.62 & 0.48 & 17.5 & 3.7 \\
\hline \multicolumn{10}{|c|}{ External validation (20.2\% pre-test probability) } \\
\hline Nomogram & $\begin{array}{l}0.81(0.79- \\
0.84)\end{array}$ & $<0.001$ & 69.4 & 79.8 & 70.9 & 2.75 & 0.29 & 41 & 6.7 \\
\hline NEWS & $\begin{array}{l}0.76(0.73- \\
0.79)\end{array}$ & $<.001$ & 5 & 62.4 & 78.6 & 2.92 & 0.48 & 42.5 & 10.8 \\
\hline BISAP & $\begin{array}{l}0.75(0.72- \\
0.78)\end{array}$ & $<.001$ & 2 & 53.4 & 84.3 & 3.41 & 0.55 & 46.3 & 12.3 \\
\hline APACHE II & $\begin{array}{l}0.75(0.72- \\
0.78)\end{array}$ & $<.001$ & 9 & 56.2 & 80.8 & 2.92 & 0.54 & 42.6 & 12.1 \\
\hline SIRS & $\begin{array}{l}0.73(0.70- \\
0.76)\end{array}$ & $<.001$ & 2 & 68.0 & 69.2 & 2.21 & 0.46 & 35.9 & 10.5 \\
\hline Glasgow & $\begin{array}{l}0.78(0.75- \\
0.81)\end{array}$ & $<0.001$ & 3 & 59.6 & 82.5 & 3.4 & 0.49 & 46.3 & 11.1 \\
\hline SOFA & $\begin{array}{l}0.80(0.77- \\
0.83)\end{array}$ & $<0.001$ & 2 & 63.5 & 85.0 & 4.24 & 0.43 & 51.8 & 9.8 \\
\hline \multicolumn{10}{|c|}{$\begin{array}{l}\text { AUC, area under curve; PLR, positive likelihood ratio; NLR, negative likelihood ratio; Post_Prob_Pos, post-test probability of a positive test; } \\
\text { Post_Prob_Neg, post-test probability of a negative test; NEWS, National Early Warning Score; BISAP, Bedside Index for Severity in Acute Pancreatitis; } \\
\text { APACHE II, Acute Physiology and Chronic Health Examination II; SIRS, Systemic Inflammatory Response Syndrome; SOFA, Sequential Organ Failure } \\
\text { Assessment. }\end{array}$} \\
\hline
\end{tabular}


There was 5.5\% (45/816), 5.0\% (20/398) and 6.0\% (53/880) had infection in the training, internal and external validation cohorts, respectively. In the training cohort, the accuracy of these predictors was generally low with BISAP $(0.75$ [0.72-0.78], PLR 4.29) having the highest predictive value compared with the other indices in training cohort (Additional file 2: Table S3; upper panel), but there was no statistical difference between any of them (Additional file 2: Table S2). In both the internal and external validation cohorts, the nomogram showed the best predictive value (highest AUC 0.78 [0.73-0.82]/0.80 [0.77-0.83]; lowest NLR 0.47/0.22; lowest post-test probability of not being major infection $2.4 \% / 1.4 \%$; Additional file 2: Table S3; middle and lower panels).

Prediction of mortality

There was $1.2 \%(10 / 816), 1.0 \%$ (4/398) and 2.3\% (20/880) mortality in the training, internal validation and external validation cohorts, respectively. All the deaths were from patients with POF in the three cohorts (12.5\%, 13.3\% and 11.2\%; Additional file 2: Table S1a-c). In both the training and external cohorts, the nomogram (AUC 0.88 [0.85-0.90], 0.89 [0.87-.91]) showed the equivalent predictive values for mortality with most of the clinical scoring systems (Additional file 2: Table S4). In the internal validation cohort, the nomogram had the highest predictive values (0.99 [0.98-1.00], PLR 32.8, NLR 0.26) for mortality, followed by BISAP (0.95 [0.92-0.97], PLR 9.85), and NEWS (0.90 [0.86-0.93], PLR 29.6, NLR 0.26), all higher than the remaining clinical scores (Additional file 2: Table S4).

\section{Discussion}

In this study, we developed and validated a mobile terminal-based nomogram for predicting POF, major infection, and mortality using six independent prognostic factors (age, respiratory rate, albumin, lactate dehydrogenase, oxygenation, and pleural effusion) that readily available on admission. This nomogram was found to be superior with the both internal and external validation cohort compared with other prognostic scores recommended for clinical use for predicting POF and major infection. As POF is the diagnostic criteria for SAP, this nomogram is recommended for routine clinical use to predict SAP on admission or to rule it out (validation NLR 0.11/0.29). Therefore, these findings encourage the use of the simple-to-use web-based nomogram before new markers are developed and introduced in our settings. The consecutive nature of patient recruitment and short time from onset of pain to admission, stringently applied in two large different Chinese centers, adds strength to these conclusions.

Age is recognized as an individual risk factor for increased severity of AP and has been used by several prognostic scores [12, 13] and practice guidelines [49-51]. To investigate the role of age and comorbidity in the severity of AP, Frey et al. [52] carried out a retrospective study in 84,713 patients with a first-attack AP. They found that the 65 to 75 age group, and age $>75$ are strong predictors of early death with an odds ratio (OR) of 2.6 and 5.2, respectively. Similar findings also applied to patients with two chronic comorbidities (OR: 3.5$)$ or $\geq 3$ comorbidities (OR: 7.4). Moreover, the mortality rate was only $0.1 \%(14 / 14,280)$ for younger patients (age < 55$)$ without chronic comorbidities compared to $5.9 \%(701 / 24,852)$ for elderly patients (age > 64) with $\geq 3$ comorbidities in the first 14 days. In addition, they showed that recent cancer, heart failure, and renal and liver diseases are strongly correlated with outcomes. Further, in acute interstitial AP, which is known to have low mortality, the Charlson comorbidity index was strongly associated with adverse clinical outcomes [53]. Because of the significant impact of the degree and number of comorbidities on clinical outcomes, we therefore excluded patients with advanced (end-stage) comorbidities with an emphasizing on assessing the intrinsic prognostic factors for AP severity.

Hypoalbuminemia occur in critically ill patients due to several factors including dilution from resuscitation, increased interstitial loss, altered liver function, and catabolic nutritional state [54]. It is strongly associated with poor clinical outcomes in acutely ill patients [55] and it has also been shown to independently associated with POF and mortality in AP patients [56, 57]. Whitcomb et al. [58] has recently found that albumin dropped rapidly in AP patients with multiple organ failure resulting in unregulated capillary leak with continued loss of larger plasma proteins. In contrast, the plasma albumin levels only dropped slightly in patients without multiple organ failure who tended to recover quickly unless they develop complications (infected pancreatic necrosis or sepsis). The therapeutic effect of albumin in inflammatory states is not only by affecting plasma volume dilation, but also by regulating inflammation and oxidative stress $[59,60]$. Therefore, serum albumin level has been incorporated in some AP severity prognostic indices (Glasgow criteria [41] and nomogram [18]).

Raised lactate levels has been observed in many critical acute illness situations including sepsis [61] and AP [62-64]. Elevated lactate may serve as a protective mechanism and has been shown to reduce Toll-like receptor and inflammasome-mediated pancreatic and liver injury via its receptor GPR81 [65]. LDH can reversibly catalyze the oxidation of lactate to pyruvate and has been employed by Ranson, Glasgow, Japanese Severity Score [13], and a nomogram [17] for early AP severity prediction and reported as a simple and useful parameter for predicting POF [66, 67], and pancreatic necrosis [68]. Moreover, urinary LDH has also been reported as an useful biomarker for septic acute kidney injury [69].

Respiratory rate and oxygen support reflect respiratory status and with respiratory failure as one most common organ dysfunction in AP [9], the early recognition of respiratory dysfunction is considered important. Our results showed a positive association between the development of POF and an increased respiratory rate or requirement for oxygen support on admission. Therefore, both respiratory rate and oxygen support have been adopted in NEWS [38] for their convenience and prognostic value. The significance of pleural effusion in AP patients has been long reported [70], and is part of BISAP [40]. Our results showed that pleural effusion (odds ratio: $3.6195 \% \mathrm{Cl} 1.97-6.6, P<0.001$ ) was an independent predictor for SAP, consistent with a previous study [71]. 
In our univariate analysis before establishing the predictive nomogram, we also found white blood cell count [13], glucose [13, 72], urea (or blood urea nitrogen) [6, 13], creatinine [13], and ionized calcium [13] were independent individual prognostic factors for POF, consistent with previously published literature. However, when these parameters were fitted into our multiple logistic regression model, they only had negligible impact on the final nomogram. Unlike most previously published studies included high proportion of SAP patients, we used a training consecutive cohort constituted only up to $10 \%$ of SAP patients which may partially explain different weights of individual prognostic factors in varied epidemiology situations. For example, three of the four existing predictive nomograms for AP severity were conducted in the ICU settings which cannot be generalizable for emergence departments or general wards where patients are primarily admitted.

Some of the six independent prognostic factors of our nomogram are included as part of NEWS (respiratory rate and oxygen support) and BISAP (age, respiratory rate, and pleural effusion), the two that we found had justifiable good predictive values for POF in both our training and internal validation cohorts. However, the nomogram was simpler than BISAP and more AP-specific than NEWS to quantitatively predict clinical outcomes in a personalized way. In addition, we validated the nomogram in another Chinese tertiary hospital with the etiological composition different from ours. The results showed that the nomogram with stable clinical applicability in both AP cohorts with hypertriglyceridemia (internal validation) or biliary (external validation) as the main etiology, adding strength to its applicability.

Our study also has some limitations. Firstly, the nomogram model was developed mainly based on the variables that were easy to get in our retrospective sets, but did not include other factors that may influence the precision of the model. For example, the oxygenation index was not included in our analysis because only paucity data were available. In a most recent study [73], the authors found that oxygenation index had low prognostic power (AUC 55.3\%) for acute respiratory distress syndrome. Secondly, the nomogram did not have specific markers for circulatory and renal failure. The reasons for this may be attributed to low incidence of circulatory and renal failure of the study population and at the early disease stage respiratory failure commonly precedes other organ failures $[5,8]$. Thirdly, the lack of international validation may limit the extrapolation and generalizability of the nomogram.

\section{Conclusions}

Our nomogram based on six readily available factors accurately predicted POF on admission in patients with AP. This nomogram can be routinely used for early AP severity prediction in our clinical practice if further validated in multiple center studies.

\section{Abbreviations}

AP: acute pancreatitis; POF: persistent organ failure; SAPS: severe acute pancreatitis; RAC: revised Atlanta classification; MIMIC-III: Medical Information Mart for Intensive Care III; elCU-CRD: elCU Collaborative Research Database; WCH/SCU: West China Hospital of Sichuan University; NEWS: National Early Warning Score; SIRS: Systemic Inflammatory Response Syndrome; BISAP: Bedside Index for Severity in Acute Pancreatitis; APACHE: Acute Physiology and Chronic Health Examination; SOFA: Sequential Organ Failure Assessment; C-index: concordance index; DCA: decision curve analysis; CIC: clinical impact curve; AUC: area under curve; ROC: receiver operating characteristic; Cl: confidence intervals; PLR: positive likelihood ratio; NLR: negative likelihood ratio; LDH: lactate dehydrogenase.

\section{Declarations}

\section{Ethics approval and consent to participate}

This study was approved by the Institutional Review Board of West China Hospital of Sichuan University and The First Affiliated Hospital of Nanchang University.

\section{Consent for publication}

All authors have provided consent for publication of the manuscript.

\section{Availability of data and materials}

The datasets used and/or analyzed during the current study are available from the corresponding author on reasonable request.

\section{Competing interests}

The authors declare that they have no competing interests.

\section{Funding}

NZ-China Strategic Research Alliance 2016 Award (China: 2016YFE0101800, QX, TJ, WH and LD; New Zealand: JAW); Key Research and Development Program of Science and Technology Department of Sichuan Province (2020YFS0235, NS; 2019YFS0259, XZ); Key Research and Development Program from the Science and Technology Department of Jiangxi Province (20192ACBL20037,YZ) National Natural Science Foundation of China (81973632, WH; 81774120, QX; 81960128, YZ); and National Institute for Health Research (NIHR) Senior Investigator Award (RS). 
QX, WH, and YZ obtained funding, and concepted, designed and supervised the study. NS collected, analyzed all retrospective and prospective data of Chengdu center, and drafted the manuscript. XZ collected and analyzed all retrospective data. WHe, LX, NL, and YZ provided and analyzed external validation datasets. LL, WC, LY, XY (Xinmin Yang) and RZ supported collecting data. PZ assisted data analysis. LD, TJ, ZL and KJ audited data quality. GJ and XY (XiaonanYang) supervised the patients' treatment. WH and QX designed, TW and PS assisted, RS reviewed the proforma and e-database. VKS, RS, and JAW had important intelligence input. WH and JAW critically revised the manuscript. All authors read and approved the final manuscript.

\section{Acknowledgements}

The authors thank all the participants and attending physicians for their contributions.

\section{References}

1. Dellinger EP, Forsmark CE, Layer P, Lévy P, Maraví-Poma E, Petrov MS, Shimosegawa T, Siriwardena AK, Uomo G, Whitcomb DC, Windsor JA: Determinant-based classification of acute pancreatitis severity: an international multidisciplinary consultation. Ann Surg 2012, 256:875-880.

2. Mederos MA, Reber HA, Girgis MD: Acute Pancreatitis: A Review. JAMA 2021, 325:382-390.

3. Petrov MS, Shanbhag S, Chakraborty M, Phillips AR, Windsor JA: Organ failure and infection of pancreatic necrosis as determinants of mortality in patients with acute pancreatitis. Gastroenterology 2010, 139:813-820.

4. Werge M, Novovic S, Schmidt PN, Gluud LL: Infection increases mortality in necrotizing pancreatitis: A systematic review and meta-analysis. Pancreatology 2016, 16:698-707.

5. Guo Q, Li A, Xia Q, Liu X, Tian B, Mai G, Huang Z, Chen G, Tang W, Jin X, et al: The role of organ failure and infection in necrotizing pancreatitis: a prospective study. Ann Surg 2014, 259:1201-1207.

6. Liu T, Huang W, Szatmary P, Abrams ST, Alhamdi Y, Lin Z, Greenhalf W, Wang G, Sutton R, Toh CH: Accuracy of circulating histones in predicting persistent organ failure and mortality in patients with acute pancreatitis. Br J Surg 2017, 104:1215-1225.

7. Sternby H, Bolado F, Canaval-Zuleta HJ, Marra-Lopez C, Hernando-Alonso Al, Del-Val-Antonana A, Garcia-Rayado G, Rivera-Irigoin R, Grau-Garcia FJ, Oms L, et al: Determinants of Severity in Acute Pancreatitis: A Nation-wide Multicenter Prospective Cohort Study. Ann Surg 2019, 270:348-355.

8. Schepers NJ, Bakker OJ, Besselink MG, Ahmed Ali U, Bollen TL, Gooszen HG, van Santvoort HC, Bruno MJ, Dutch Pancreatitis Study G: Impact of characteristics of organ failure and infected necrosis on mortality in necrotising pancreatitis. Gut 2019, 68:1044-1051.

9. Shi N, Liu T, de la Iglesia-Garcia D, Deng L, Jin T, Lan L, Zhu P, Hu W, Zhou Z, Singh V, et al: Duration of organ failure impacts mortality in acute pancreatitis. Gut 2020, 69:604-605.

10. Banks PA, Bollen TL, Dervenis C, Gooszen HG, Johnson CD, Sarr MG, Tsiotos GG, Vege SS, Acute Pancreatitis Classification Working G: Classification of acute pancreatitis-2012: revision of the Atlanta classification and definitions by international consensus. Gut 2013, 62:102-111.

11. Ranson JH, Rifkind KM, Roses DF, Fink SD, Eng K, Spencer FC: Prognostic signs and the role of operative management in acute pancreatitis. Surg Gynecol Obstet 1974, 139:69-81.

12. Di MY, Liu H, Yang ZY, Bonis PA, Tang JL, Lau J: Prediction Models of Mortality in Acute Pancreatitis in Adults: A Systematic Review. Ann Intern Med 2016, 165:482-490.

13. Mounzer R, Langmead CJ, Wu BU, Evans AC, Bishehsari F, Muddana V, Singh VK, Slivka A, Whitcomb DC, Yadav D, et al: Comparison of existing clinical scoring systems to predict persistent organ failure in patients with acute pancreatitis. Gastroenterology 2012, 142:1476-1482; quiz e14151476.

14. Yang CJ, Chen J, Phillips AR, Windsor JA, Petrov MS: Predictors of severe and critical acute pancreatitis: a systematic review. Dig Liver Dis 2014, 46:446-451.

15. van den Berg FF, de Bruijn AC, van Santvoort HC, Issa Y, Boermeester MA: Early laboratory biomarkers for severity in acute pancreatitis; $A$ systematic review and meta-analysis. Pancreatology 2020, 20:1302-1311.

16. Jiang X, Su Z, Wang Y, Deng Y, Zhao W, Jiang K, Sun C: Prognostic nomogram for acute pancreatitis patients: An analysis of publicly electronic healthcare records in intensive care unit. J Crit Care 2019, 50:213-220.

17. Zheng W, Zhang YJ, Liu R, Zhao XD, Ai H: Prediction of gastrointestinal bleeding events in patients with acute coronary syndrome undergoing percutaneous coronary intervention: An observational cohort study (STROBE compliant). Medicine (Baltimore) 2020, 99 :e21312.

18. Xu X, Ai F, Huang M: Deceased serum bilirubin and albumin levels in the assessment of severity and mortality in patients with acute pancreatitis. Int J Med Sci 2020, 17:2685-2695.

19. Cao X, Wang HM, Lu R, Zhang XH, Qu YL, Wang L, Wang SL, Bai SW, Liu X, Ma L, et al: Establishment and verification of a nomogram for predicting severe acute pancreatitis. Eur Rev Med Pharmacol Sci 2021, 25:1455-1461.

20. Zhou J, Ke L, Yang D, Chen Y, Li G, Tong Z, Li W, Li J: Predicting the clinical manifestations in necrotizing acute pancreatitis patients with splanchnic vein thrombosis. Pancreatology 2016, 16:973-978. 
21. Zhu C, Zhang S, Zhong H, Gu Z, Kang Y, Pan C, Xu Z, Chen E, Yu Y, Wang Q, Mao E: Intra-abdominal infection in acute pancreatitis in eastern China: microbiological features and a prediction model. Ann Transl Med 2021, 9:477.

22. Gupta P, Kumar MP, Verma M, Sharma V, Samanta J, Mandavdhare H, Sinha SK, Dutta U, Kochhar R: Development and validation of a computed tomography index for assessing outcomes in patients with acute pancreatitis: "SMART-CT" index. Abdom Radiol (NY) 2021, 46:1618-1628.

23. Hollemans RA, Bollen TL, van Brunschot S, Bakker OJ, Ahmed Ali U, van Goor H, Boermeester MA, Gooszen HG, Besselink MG, van Santvoort HC: Predicting Success of Catheter Drainage in Infected Necrotizing Pancreatitis. Ann Surg 2016, 263:787-792.

24. Bellam BL, Samanta J, Gupta P, Kumar MP, Sharma V, Dhaka N, Sarma P, Muktesh G, Gupta V, Sinha SK, Kochhar R: Predictors of outcome of percutaneous catheter drainage in patients with acute pancreatitis having acute fluid collection and development of a predictive model. Pancreatology 2019, 19:658-664.

25. Bevan MG, Asrani VM, Pendharkar SA, Goodger RL, Windsor JA, Petrov MS: Nomogram for predicting oral feeding intolerance in patients with acute pancreatitis. Nutrition $2017,36: 41-45$.

26. Ma JH, Yuan YJ, Lin SH, Pan JY: Nomogram for predicting diabetes mellitus after the first attack of acute pancreatitis. Eur J Gastroenterol Hepatol 2019, 31:323-328.

27. von Elm E, Altman DG, Egger M, Pocock SJ, Gotzsche PC, Vandenbroucke JP, Initiative S: Strengthening the Reporting of Observational Studies in Epidemiology (STROBE) statement: guidelines for reporting observational studies. BMJ 2007, 335:806-808.

28. Li L, Jin T, Wen S, Shi N, Zhang R, Zhu P, Lin Z, Jiang K, Guo J, Liu T, et al: Early Rapid Fluid Therapy Is Associated with Increased Rate of Noninvasive Positive-Pressure Ventilation in Hemoconcentrated Patients with Severe Acute Pancreatitis. Dig Dis Sci 2020, 65:2700-2711.

29. Zhu Y, Pan X, Zeng H, He W, Xia L, Liu P, Zhu Y, Chen Y, Lv N: A Study on the Etiology, Severity, and Mortality of 3260 Patients With Acute Pancreatitis According to the Revised Atlanta Classification in Jiangxi, China Over an 8-Year Period. Pancreas 2017, 46:504-509.

30. Zhang R, Deng L, Jin T, Zhu P, Shi N, Jiang K, Li L, Yang X, Guo J, Yang X, et al: Hypertriglyceridaemia-associated acute pancreatitis: diagnosis and impact on severity. HPB (Oxford) 2019, 21:1240-1249.

31. Nawaz H, Koutroumpakis E, Easler J, Slivka A, Whitcomb DC, Singh VP, Yadav D, Papachristou GI: Elevated serum triglycerides are independently associated with persistent organ failure in acute pancreatitis. Am J Gastroenterol 2015, 110:1497-1503.

32. Adiamah A, Psaltis E, Crook M, Lobo DN: A systematic review of the epidemiology, pathophysiology and current management of hyperlipidaemic pancreatitis. Clin Nutr 2018, 37:1810-1822.

33. van Geenen EJ, van der Peet DL, Bhagirath P, Mulder CJ, Bruno MJ: Etiology and diagnosis of acute biliary pancreatitis. Nat Rev Gastroenterol Hepatol 2010, 7:495-502.

34. Lee PJ, Papachristou Gl: New insights into acute pancreatitis. Nat Rev Gastroenterol Hepatol 2019, 16:479-496.

35. Easler JJ, de-Madaria E, Nawaz H, Moya-Hoyo N, Koutroumpakis E, Rey-Riveiro M, Singh VP, Acevedo-Piedra NG, Whitcomb DC, Yadav D, Papachristou GI: Patients With Sentinel Acute Pancreatitis of Alcoholic Etiology Are at Risk for Organ Failure and Pancreatic Necrosis: A DualCenter Experience. Pancreas 2016, 45:997-1002.

36. Dellinger EP, Forsmark CE, Layer P, Levy P, Maravi-Poma E, Petrov MS, Shimosegawa T, Siriwardena AK, Uomo G, Whitcomb DC, et al: Determinantbased classification of acute pancreatitis severity: an international multidisciplinary consultation. Ann Surg 2012, 256:875-880.

37. Bakker OJ, van Brunschot S, van Santvoort HC, Besselink MG, Bollen TL, Boermeester MA, Dejong CH, van Goor H, Bosscha K, Ahmed Ali U, et al: Early versus on-demand nasoenteric tube feeding in acute pancreatitis. N Engl J Med 2014, 371:1983-1993.

38. Royal College of Physicians. National Early Warning Score (NEWS): Standardising the assessment of acute illness severity in the NHS. Report of a working party. London: RCP; 2012.

39. Mofidi R, Duff MD, Wigmore SJ, Madhavan KK, Garden OJ, Parks RW: Association between early systemic inflammatory response, severity of multiorgan dysfunction and death in acute pancreatitis. Br J Surg 2006, 93:738-744.

40. Wu BU, Johannes RS, Sun X, Tabak Y, Conwell DL, Banks PA: The early prediction of mortality in acute pancreatitis: a large population-based study. Gut 2008, 57:1698-1703.

41. Blamey SL, Imrie CW, O'Neill J, Gilmour WH, Carter DC: Prognostic factors in acute pancreatitis. Gut 1984, 25:1340-1346.

42. Larvin M, McMahon MJ: APACHE-II score for assessment and monitoring of acute pancreatitis. Lancet 1989, 2:201-205.

43. Halonen KI, Pettilä V, Leppäniemi AK, Kemppainen EA, Puolakkainen PA, Haapiainen RK: Multiple organ dysfunction associated with severe acute pancreatitis. Crit Care Med 2002, 30:1274-1279.

44. Steyerberg EW, Vergouwe Y: Towards better clinical prediction models: seven steps for development and an ABCD for validation. Eur Heart J 2014, 35:1925-1931.

45. Kerr KF, Brown MD, Zhu K, Janes H: Assessing the Clinical Impact of Risk Prediction Models With Decision Curves: Guidance for Correct Interpretation and Appropriate Use. J Clin Oncol 2016, 34:2534-2540.

46. Vickers AJ, Elkin EB: Decision curve analysis: a novel method for evaluating prediction models. Med Decis Making 2006, 26:565-574.

47. Mandrekar JN: Receiver operating characteristic curve in diagnostic test assessment. J Thorac Onco/ 2010, 5:1315-1316.

48. DeLong ER, DeLong DM, Clarke-Pearson DL: Comparing the areas under two or more correlated receiver operating characteristic curves: a nonparametric approach. Biometrics 1988, 44:837-845.

Page 15/19 
49. Working Group IAPAPAAPG: IAP/APA evidence-based guidelines for the management of acute pancreatitis. Pancreatology 2013, $13:$ e1-15.

50. Yokoe M, Takada T, Mayumi T, Yoshida M, Isaji S, Wada K, Itoi T, Sata N, Gabata T, Igarashi H, et al: Japanese guidelines for the management of acute pancreatitis: Japanese Guidelines 2015. J Hepatobiliary Pancreat Sci 2015, 22:405-432.

51. Leppaniemi A, Tolonen M, Tarasconi A, Segovia-Lohse H, Gamberini E, Kirkpatrick AW, Ball CG, Parry N, Sartelli M, Wolbrink D, et al: 2019 WSES guidelines for the management of severe acute pancreatitis. World J Emerg Surg 2019, 14:27.

52. Frey C, Zhou H, Harvey D, White RH: Co-morbidity is a strong predictor of early death and multi-organ system failure among patients with acute pancreatitis. J Gastrointest Surg 2007, 11:733-742.

53. Singh VK, Bollen TL, Wu BU, Repas K, Maurer R, Yu S, Mortele KJ, Conwell DL, Banks PA: An assessment of the severity of interstitial pancreatitis. Clin Gastroenterol Hepatol 2011, 9:1098-1103.

54. Vincent JL, Russell JA, Jacob M, Martin G, Guidet B, Wernerman J, Ferrer R, McCluskey SA, Gattinoni L: Albumin administration in the acutely ill: what is new and where next? Crit Care 2014, 18:231.

55. Vincent $\mathrm{JL}$, Dubois MJ, Navickis RJ, Wilkes MM: Hypoalbuminemia in acute illness: is there a rationale for intervention? A meta-analysis of cohort studies and controlled trials. Ann Surg 2003, 237:319-334.

56. Hong W, Lin S, Zippi M, Geng W, Stock S, Basharat Z, Cheng B, Pan J, Zhou M: Serum Albumin Is Independently Associated with Persistent Organ Failure in Acute Pancreatitis. Can J Gastroenterol Hepatol 2017, 2017:5297143.

57. Li S, Zhang Y, Li M, Xie C, Wu H: Serum albumin, a good indicator of persistent organ failure in acute pancreatitis. BMC Gastroentero/ 2017 , 17:59.

58. Komara NL, Paragomi P, Greer PJ, Wilson AS, Breze C, Papachristou GI, Whitcomb DC: Severe acute pancreatitis: capillary permeability model linking systemic inflammation to multiorgan failure. Am J Physiol Gastrointest Liver Physiol 2020, 319:G573-G583.

59. Artigas A, Wernerman J, Arroyo V, Vincent JL, Levy M: Role of albumin in diseases associated with severe systemic inflammation: Pathophysiologic and clinical evidence in sepsis and in decompensated cirrhosis. J Crit Care 2016, 33:62-70.

60. Bernardi M, Angeli P, Claria J, Moreau R, Gines P, Jalan R, Caraceni P, Fernandez J, Gerbes AL, O'Brien AJ, et al: Albumin in decompensated cirrhosis: new concepts and perspectives. Gut 2020, 69:1127-1138.

61. Singer M, Deutschman CS, Seymour CW, Shankar-Hari M, Annane D, Bauer M, Bellomo R, Bernard GR, Chiche JD, Coopersmith CM, et al: The Third International Consensus Definitions for Sepsis and Septic Shock (Sepsis-3). JAMA 2016, 315:801-810.

62. Valverde-Lopez F, Matas-Cobos AM, Alegria-Motte C, Jimenez-Rosales R, Ubeda-Munoz M, Redondo-Cerezo E: BISAP, RANSON, lactate and others biomarkers in prediction of severe acute pancreatitis in a European cohort. J Gastroenterol Hepatol 2017, 32:1649-1656.

63. Shu W, Wan J, Chen J, He W, Zhu Y, Lu N, Xia L: Elevated arterial lactate level as an independent risk factor for pancreatic infection in moderately severe acute pancreatitis. Pancreatology 2019, 19:653-657.

64. Shu W, Wan J, Chen J, He W, Zhu Y, Zeng H, Liu P, Zhu Y, Xia L, Lu N: Initially elevated arterial lactate as an independent predictor of poor outcomes in severe acute pancreatitis. BMC Gastroenterol 2020, 20:116.

65. Hoque R, Farooq A, Ghani A, Gorelick F, Mehal WZ: Lactate reduces liver and pancreatic injury in Toll-like receptor- and inflammasome-mediated inflammation via GPR81-mediated suppression of innate immunity. Gastroenterology 2014, 146:1763-1774.

66. Cui J, Xiong J, Zhang Y, Peng T, Huang M, Lin Y, Guo Y, Wu H, Wang C: Serum lactate dehydrogenase is predictive of persistent organ failure in acute pancreatitis. J Crit Care 2017, 41:161-165.

67. Tian F, Li H, Wang L, Li B, Aibibula M, Zhao H, Feng N, LV J, Zhang G, Ma X: The diagnostic value of serum C-reactive protein, procalcitonin, interleukin- 6 and lactate dehydrogenase in patients with severe acute pancreatitis. Clin Chim Acta 2020, 510:665-670.

68. Komolafe O, Pereira SP, Davidson BR, Gurusamy KS: Serum C-reactive protein, procalcitonin, and lactate dehydrogenase for the diagnosis of pancreatic necrosis. Cochrane Database Syst Rev 2017, 4:CD012645.

69. Bagshaw SM, Langenberg C, Haase M, Wan L, May CN, Bellomo R: Urinary biomarkers in septic acute kidney injury. Intensive Care Med 2007, 33:1285-1296.

70. Gumaste V, Singh V, Dave P: Significance of pleural effusion in patients with acute pancreatitis. Am J Gastroentero/ 1992, 87:871-874.

71. He F, Zhu HM, Li BY, Li XC, Yang S, Wang Z, Zhang M: Factors predicting the severity of acute pancreatitis in elderly patients. Aging Clin Exp Res 2021, 33:183-192.

72. Yang X, Zhang R, Jin T, Zhu P, Yao L, Li L, Cai W, Mukherjee R, Du D, Fu X, et al: Stress Hyperglycemia Is Independently Associated with Persistent Organ Failure in Acute Pancreatitis. Dig Dis Sci 2021.

73. Liu Y, Liu J, Huang L: A Simple-to-Use Web-Based Calculator for Survival Prediction in Acute Respiratory Distress Syndrome. Front Med (Lausanne) 2021, 8:604694.

\section{Figures}


Fig 1

A

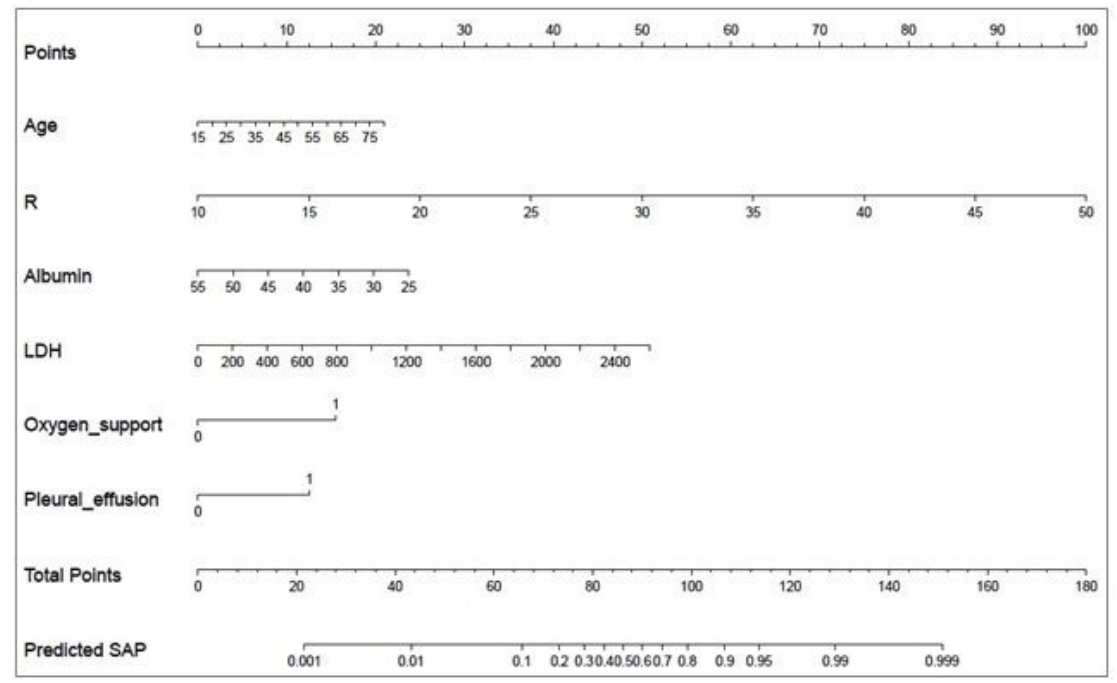

\section{B}

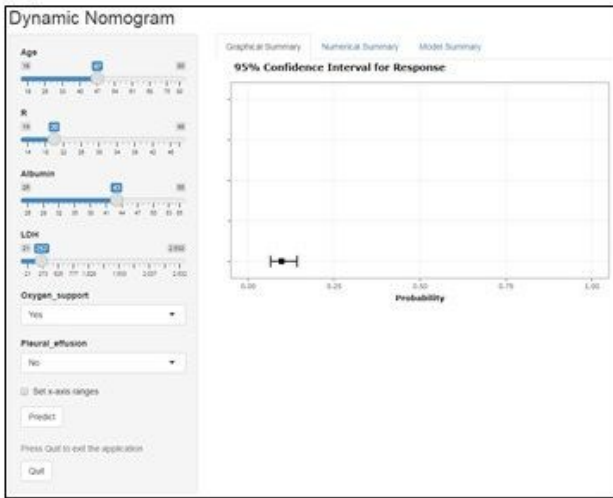

\section{C}

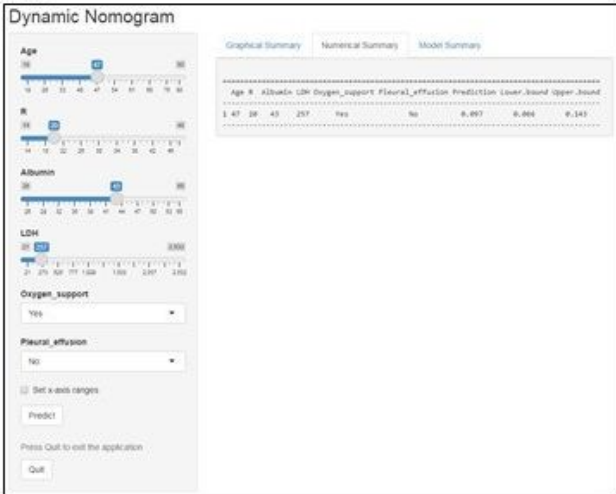

\section{Figure 1}

Nomogram for predicting POF in patients with AP and dynamic web-based calculator. The score for each value is assigned by drawing a line upward to the points line, and the sum of the six scores is plotted on the total points line (A). Web POF rate calculator with $95 \% \mathrm{Cl}$ in both graphical (B) and numerical (C) summary. 
Fig 2

A

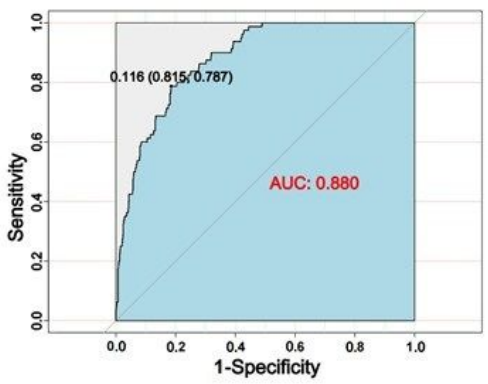

C

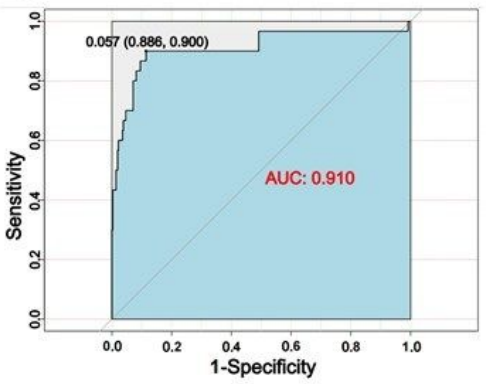

E

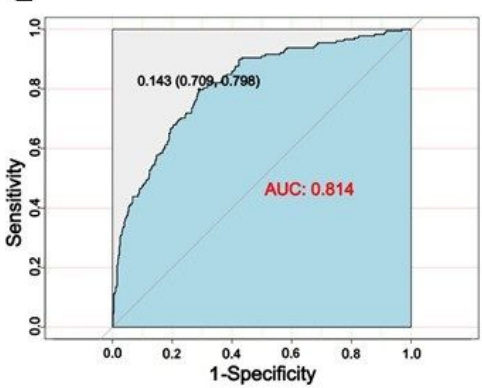

B

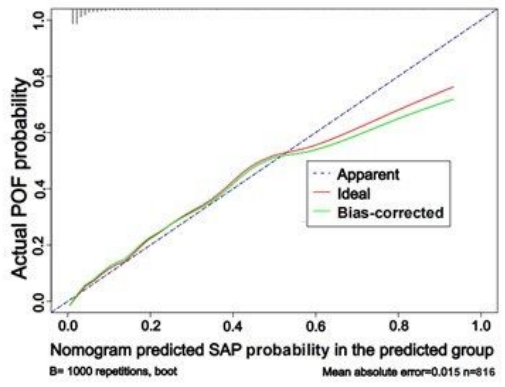

D

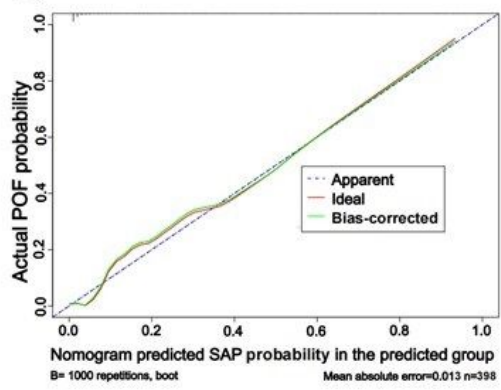

F

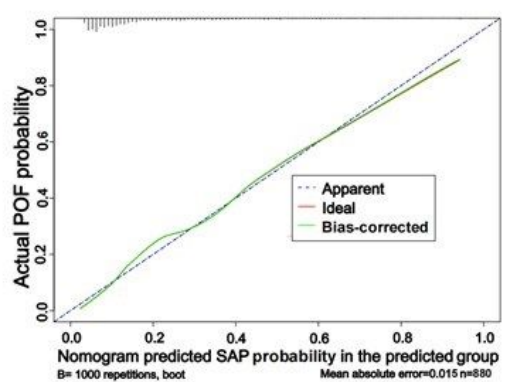

Figure 2

Assessment of the nomogram in all three cohorts. The accuracy of the model was determined using AUC analysis and the distribution of the predicted probabilities presented by calibration curve for cohorts of the training $(A, B)$, internal validation $(C, D)$, and external validation $(E, F)$. 
Fig 3
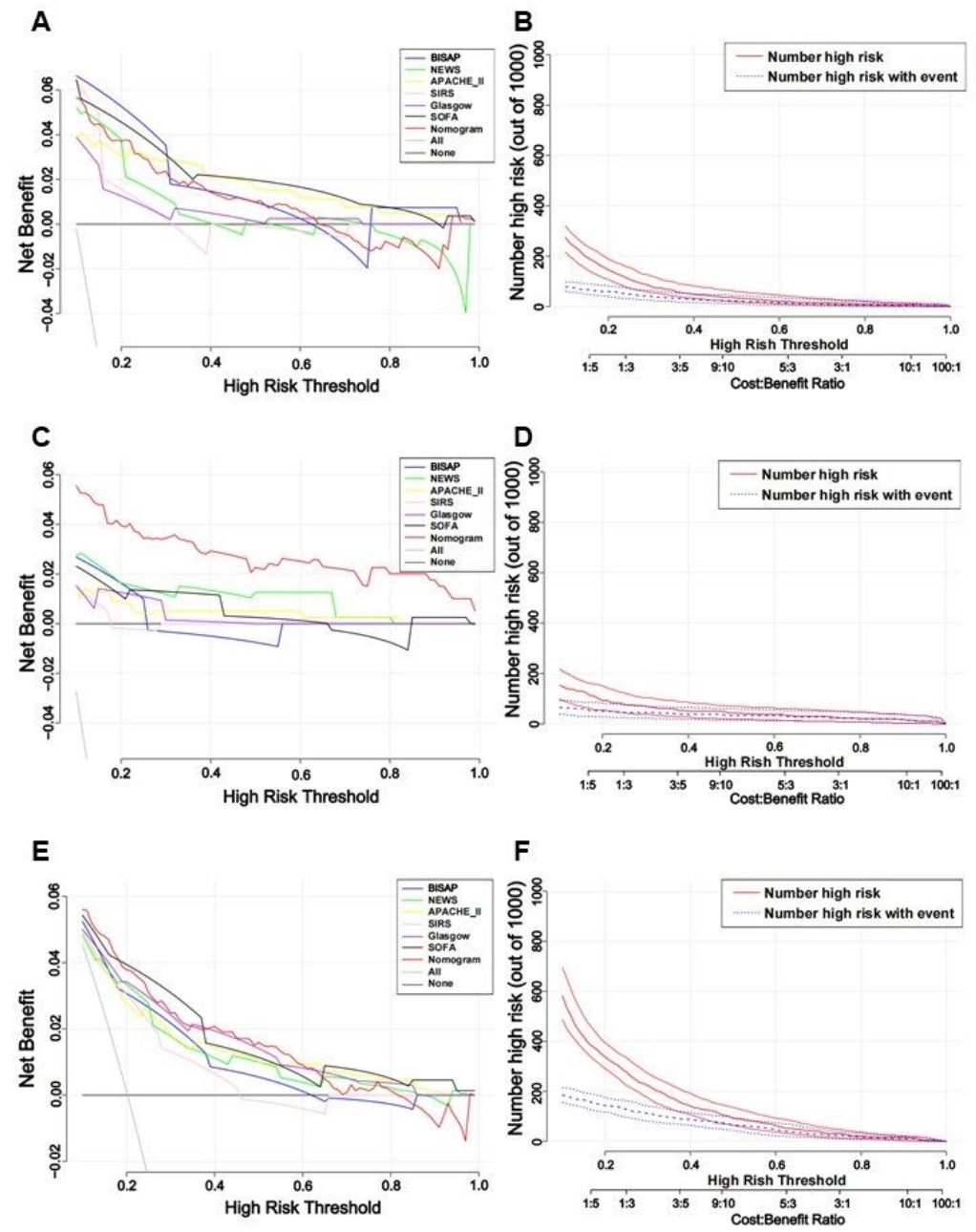

\section{Figure 3}

Clinical utility of the nomogram. The DCA and CIC of the nomogram for predicting POF in cohorts of training (A, B), internal validation (C, D), and external validation $(E, F)$.

\section{Supplementary Files}

This is a list of supplementary files associated with this preprint. Click to download.

- Additionalfile12021.07.26.pptx

- Additionalfile22021.07.26.docx 